This item was submitted to Loughborough's Research Repository by the author.

Items in Figshare are protected by copyright, with all rights reserved, unless otherwise indicated.

\title{
Visualizing the hotspots and emerging trends of 3D printing through scientometrics
}

PLEASE CITE THE PUBLISHED VERSION

https://doi.org/10.1108/RPJ-05-2017-0100

\section{PUBLISHER}

(C) Emerald Publishing Limited

\section{VERSION}

AM (Accepted Manuscript)

\section{PUBLISHER STATEMENT}

This work is made available according to the conditions of the Creative Commons Attribution-NonCommercialNoDerivatives 4.0 International (CC BY-NC-ND 4.0) licence. Full details of this licence are available at: https://creativecommons.org/licenses/by-nc-nd/4.0/

\section{LICENCE}

CC BY-NC-ND 4.0

\section{REPOSITORY RECORD}

Jin, Yuran, Xin Li, lan Campbell, and Shoufeng Ji. 2018. "Visualizing the Hotspots and Emerging Trends of 3D Printing Through Scientometrics". Loughborough University. https://hdl.handle.net/2134/25443. 


\title{
Visualizing the Hotspots and Emerging Trends of 3D Printing through Scientometrics
}

\begin{abstract}
Purpose - 3D printing is believed to be driving the third industrial revolution. A comprehensive understanding of the hotspots and trends of 3D printing may promote the theory development of 3D printing, help researchers to determine the research direction, and provide a reference for enterprises and government to plan the development of 3D printing industry. However, a scientometric visualizing of 3D printing research and an exploration its hotspots and emerging trends are lacking. Therefore, it was necessary to carry out this relevant research.
\end{abstract}

Design/methodology/approach - Based on the theory of scientometrics, 2769 literatures on the 3D printing theme were found in the Web of Science Core Collection' SCI indexes between 1995-2016. These were analyzed to explore the research hotspots and emerging trends of 3D printing with the software CiteSpacellI.

Findings - (1) hotspots appeared first in 1993, grow rapidly from 2005, and peaked in 2013; (2) hotspots in the "medical field" appeared earliest and have remained extremely active; (3) hotspots have evolved from "drug", "printer", "rapid prototyping" and "3D printing" in the 1990s, through "laser-induced consolidation", "scaffolds", "sintering" and "metal matrix composites" in the 2000s, to the current hotspots of "stereolithography", "laser additive manufacturing", "medical images", etc.; (4) "3D bioprinting","titanium", "stem cell" and "chemical reaction" were the emerging hotspots in recent years; (5) "commercial operation" and "fusion with emerging technology such as big data" may create future hotspots.

Research limitations/implications - It is hard to avoid the possibility of missing important research results on 3D printing. The relevant records could be missing if the query phrases for topic search do not appear in records. Besides, in order to improve the quality of data, this study selected articles and reviews as the research objects, which may also omit some records.

Originality/value - First, this is the first paper visualizing the hotspots and emerging trends of 3D printing using scientometric tools. Second, not only "burst reference" and "burst keywords", but also "cluster" and "landmark article" are also selected as the evaluation factors to judge the hotspots and trends of a domain comprehensively. Third, overall perspective of hotspots and trends of 3D printing is put forward for the first time.

Keywords - 3D printing, Additive manufacturing, Rapid prototyping, Scientometrics, CiteSpace, Visualization, Research hotspots, Emerging trends

Paper type - research article 


\section{Introduction}

3D printing is changing the world. It is believed by some to be driving a new industrial revolution (Economist, 2012). American Time magazine has listed 3D printing as one of the top ten fastest-growing industries (Lipson and Kurman, 2013). 3D printing could play a significant part in future economic growth, and is considered to be a disruptive technique according to the disruption pattern (Christensen, 2013). Therefore, 3D printing has been widely investigated by many governments, research institutions, enterprises and media (Ratto and Ree, 2012; Wang and Su, 2015). In developed countries, particularly in the United States, 3D printing has been in widespread use for a long time (Klein et al., 2013). Some developing countries have also begun to focus on this technology. For example, China as the largest developing country incorporated 3D printing into its 863 plan ( $\mathrm{Jin}$ and $\mathrm{Ji}, 2013$ ), and the 3D printing industry has achieved rapid development in recent years.

$3 \mathrm{D}$ printing is a process of joining materials to make objects from 3D model data, usually layer by layer (ASTMInternational, 2012). Contrary to traditional subtractive manufacturing. 3D printing is a material addition technology capable of creating complex shapes similar to casting, forming and injection moulding (R. I. Campbell et al., 2012). 3D printing has the characteristics of fast set-up and geometric freedom (Lipson and Kurman, 2013). Compared to traditional manufacturing technology, it is simpler, sometimes cheaper, and often more convenient to use ( $\underline{T}$. Campbell et al., 2011). In particular, 3D printing technology can produce an assembly with complex structures in a single-step process (Chua and Leong, 2004). It also helps the environment through the flexibility that allows manufacturers to optimize designs for lightweighting and lean production (Karjalainen et al., 2007) so as to reduce the use of resources(Chu et al., 2008). More than 100 kinds of raw materials can be used with 3D printing, such as hot plastic, metal, nylon, acrylic, gypsum, metal alloys, ceramics, wax, sand, stone, paper, rubber, edible materials and so on (Bassoli et al., 2007; Kneissl, 2013). Depending on the material and machine technology used, 3D printing (Additive Manufacturing) has been classified into 7 categories, namely VAT Photopolymerisation, Material Jetting, Binder Jetting, Material Extrusion and Powder Bed Fusion(ASTMInternational, 2012). 3D printing has been applied in a variety of industries, such as aerospace (T. Campbell et al., 2011; Lee et al., 2016), automotive (Guo and Leu, 2013; Rahim and Maidin, 2014), biomedical (Gebhardt et al., 2010; Hutmacher, 2015; Marga et al., 2012; Melchels et al., 2012), building and construction (Perkins and Skitmore, 2015; Song and Hu, 2015; Valkenaers et al., 2014), marine and offshore (Bhudolia et al., 2015; Chua et al., 2016; Tham et al., 2015), food industry (Lipton et al., 2015; Sun, Peng, et al., 2015; Sun, Zhou, et al., 2015), 
environmental engineering (Bara et al., 2013; Cho et al., 2015; Mathai, 2015), as well as desalination and water treatment (Andersson et al., 1985; Johnson et al., 1993).

The related academic studies on 3D printing are rapidly increasing (Bhasin and Bodla, 2014). An investigation conducted by the authors showed the annual number of published and cited papers retrieved by a topic search on the Web of Science has grown rapidly in recent years, as shown in Figure 1 and Figure 2.

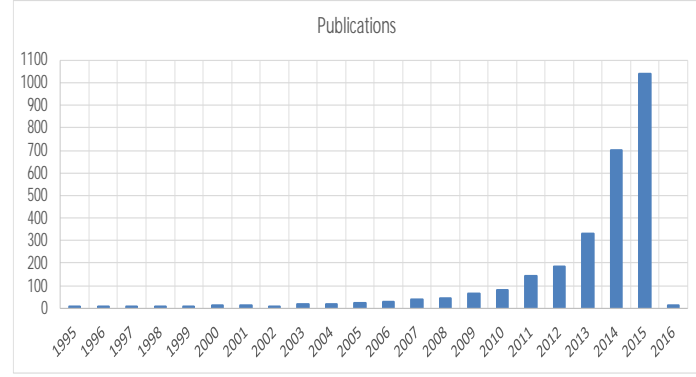

Figure 1 Published articles each year

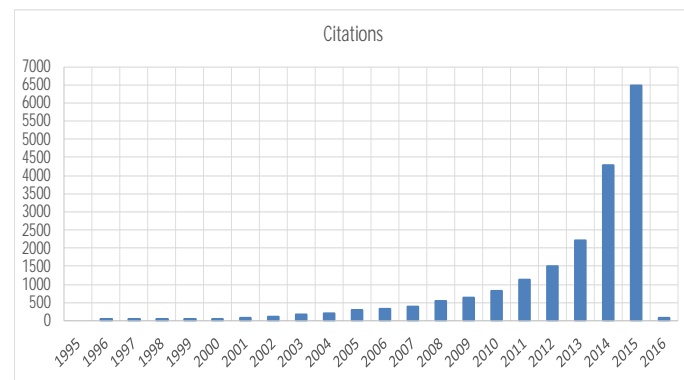

Figure 2 Cited times of the articles each year

The research topics around 3D printing are also varied. Figure 3, called a Foam Tree shows, the trending topics according to information obtained from the internet, which is drawn by the Lingo clustering method based on the platform of Carrot 2 (http://project.carrot2.org/). The left-hand figure is based on the first 100 results of a Bing search and shows that "additive manufacturing technology", "rapid additive manufacturing" and "additive manufacturing processes" are the research hotspots. The right-hand figure is based on the top 100 results of a PubMed search and shows that "tissue engineering", "resulting implant" and "preparation" are in high usage as keywords relating to 3D printing. The results from this simplistic survey provided a basic understanding for the following research. In this research, scholarly publications were investigated as a more rigorous and reliable representation of the relevant literature as found through the Web of Science. 

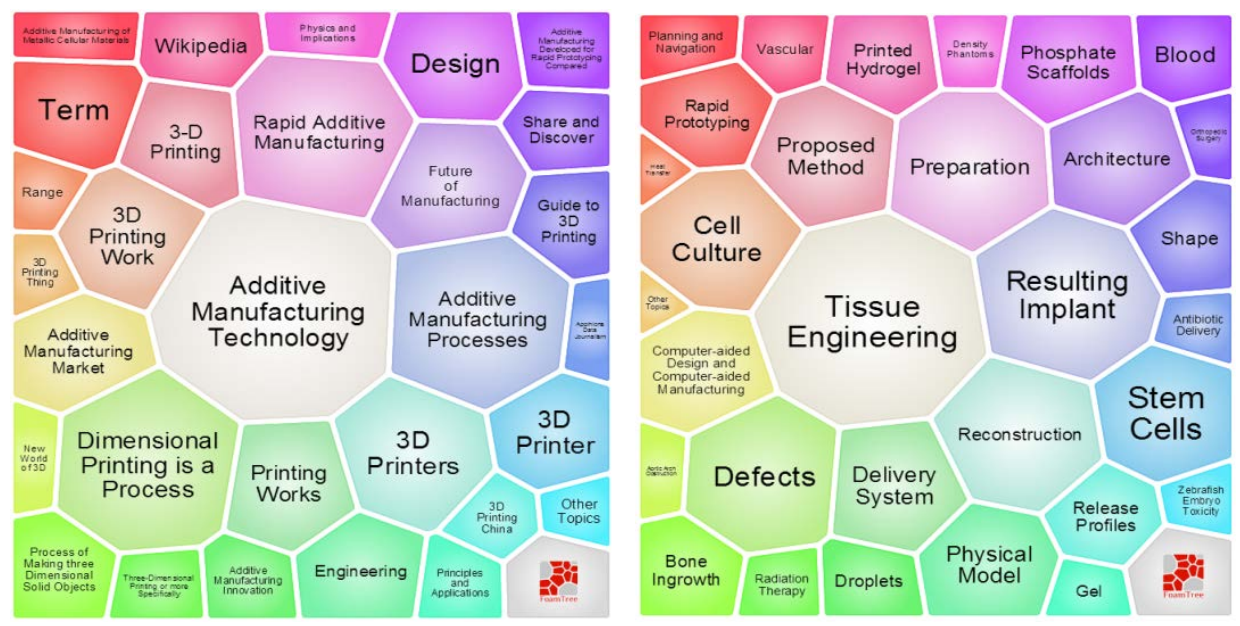

Figure 3 A lightweight survey of major topics on 3D printing

Combined with existing related research and the authors' preliminary investigation, it was found that firstly, a scientometric research mapping of 3D printing is lacking in spite of the increase of research activities and research topics. This paper will visualize the intellectual landscapes and identify the hotspots and trends of 3D printing through cluster analysis, co-cited references and co-occurring keywords using a scientometric tool. Secondly, previous studies on the hotspots and frontiers of a certain field were mainly dependent on experts, but it is difficult for experts to capture frontiers and hotspots of a domain in a timely manner. However, the scientometric method utilized can acquire a more comprehensive landscape on 3D printing. It should be noted that the computational tool used is not designed to replace expert-made reviews, but rather to provide an additional viewpoint with a certain set of benefits. The research can promote the theory development of 3D printing, help researchers to determine their research direction and focus on 3D printing, and provide a reference for enterprises and government to plan the industrial development of 3D printing.

The remainder of the paper is organized as follows: in Section 2, the authors describe the research tool and research methods and explain the data sources and structure. The hotspots and trends of 3D printing are analyzed in Section 3. Conclusions and discussion about future work are presented in Section 4

\section{Methodology}

Unlike conventional literature studies on 3D printing, this work employed a scientometric visual tool called CiteSpacelll to map the intellectual landscape of 3D printing and explore the hotspots and trends within the domain. 


\subsection{Scientometric analysis in CiteSpacellI}

Scientometric is a basic but effective method to detect and identify the emergence and development of a new technology (Serenko et al., 2010). Although there are an increasing number of science mapping systems and generic tools (Cobo et al., 2011), few systems are readily accessible and specifically designed to meet the needs for generating a systematic review of a fast-moving and complex field. CiteSpace includes features to facilitate the detection and interpretation of emerging trends and transition patterns for analysts who are not domain experts. It is designed specifically to support the complete analytic process of visualizing and analyzing scientific literature (Chen, Dubin, et al., 2014b). Therefore, the scientometric software CiteSpace

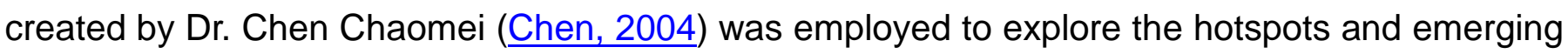
trends on 3D printing in this study.

The intellectual landscape can be depicted by the co-cited references network and co-occurring keywords network (Chen, Dubin, et al., 2014c), The co-cited references are the ones which are cited at the same time by a later publication. The co-occurring keywords are the ones which occur at the same time in a later publication. The intellectual landscape visualizes the knowledge modules and time sequence of different clusters. It can show the important topics based on the clusters and the emerging trends based on the time sequence. Citation bursts are used to find the hotspots and emerging trends of $3 \mathrm{D}$ printing. The start of a burst event is seen through the appearance of a keyword or the surging citations of an article (Chen, Dubin, et al., 2014a; Chen et al., 2010). The citation burst provides insightful guidance for navigating the development trends of a certain field through the fast-changing landscape of the keywords or references (Chen, Dubin, \& Schultz, 2014; Chen et al., 2006). It also provides evidence that the publication evidently has attracted an extraordinary degree of attention from its scientific community so as to be recognized as a hotspot (Chen, 2004, 2014). The citation burst can last for a single year or multiple years. A publication with a high number of citations can be considered as a landmark in the knowledge field (Chen et al., 2010). Since these articles can be highly cited over a long period, they may reflect the "long hotspots" of some domains. To sum up, this work explored the hotspots and trends of 3D printing mainly by identifying intellectual landscapes of clusters, burst references and keywords, and landmark references.

\subsection{Data collection}

In order to retrieve only high-quality literature on 3D printing, SCI-EXPANDED from Web of Science Core Collection was chosen as the data source. The topic query statement of the Advanced Search was TS= ("3D print*" OR "three dimensional print*" OR "additive 
manufacturing"). The function of wildcard * was to capture relevant variations of a word, such as 3D printing and 3D printed. Then, "All document types" was selected as the data type and the language set to "English". The time span of retrieval was set from 1995 to 2016 (the search date was December 13, 2015). The slice is the time interval of data retrieval such as 1 year, 5 years, etc. In our paper, the years per slice was set to 1 . The query generated 3144 original records. In order to improve the quality of analysis, the authors filtered out a set of letters, news, notes and proceeding papers that were less representative record types, and the final number of records was reduced to 2769 including 2648 research articles and 121 review papers.

\section{Hotspots and trends}

\subsection{The intellectual landscape of clusters as indicators of hotspots and trends}

The Top $\mathrm{N}=50$ algorithm was selected to generate the intellectual landscape in CiteSpacellI. Top $\mathrm{N}=50$ means that the 50 most frequently occurring (for keywords) or cited (for reference) will be selected from per slice. Figure 4 shows the overall bibliographic landscape of a co-cited references network for 3D printing, which contains 845 nodes and 2026 links from 1995 to 2016. The nodes denote co-cited references. The year shown with the top color bar from left to right is from the more distant to the more recent past. Lines that connect nodes are co-citation links, whose different colors show when a connection was made for the first time (Chen, Dubin, et al., 2014c). TFIDF (term frequency-inverse document frequency), LLR (log-likehood ratio) and MI (mutual information) are the three different algorithms used to generate cluster labels. In this review, LLR is used as the standard because it usually gives the best result in terms of the actual situation after several runs (need a reference for this). 


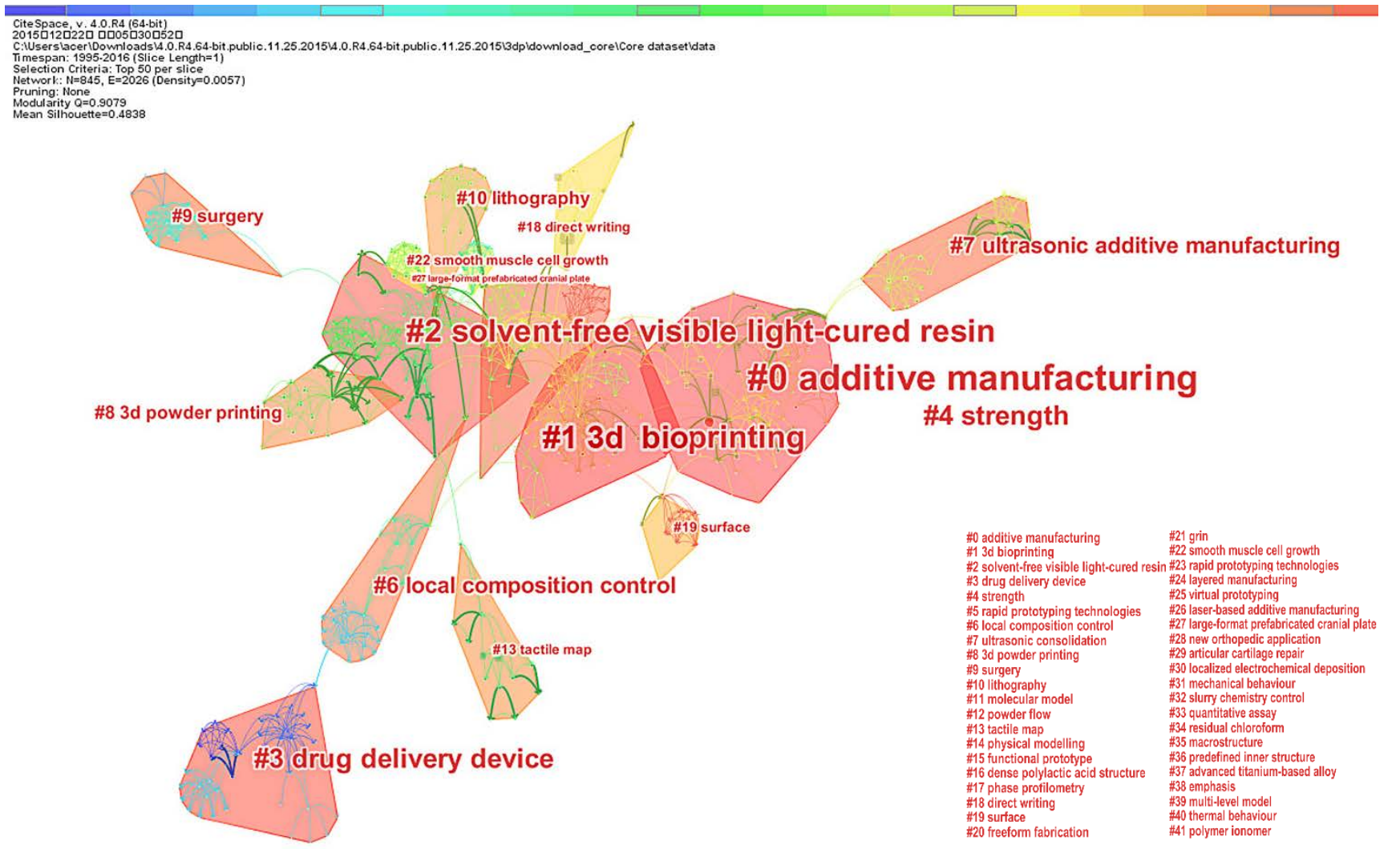

Figure 4 Co-cited references cluster view on 3D printing

The literature co-citation network in Figure 4 contains a total of 39475 documents from 1995 to 2016, and produces 42 clusters. The top 10 of the 42 clusters are shown in Table 1 . The size of each cluster represents the number of references, which reflects the intensity of the hotspot. Obviously, "additive manufacturing" is the hottest research topic followed by " $3 \mathrm{~d}$ bioprinting". The silhouette value ranges from -1 to 1 , which reflects the quality of each cluster configuration. The higher the silhouette value, the better the quality of the clustering. The year shows the average publication year of all literature in a cluster. The more recent the date, the more "frontier" is the nature of the clustering, which can embody the emerging trends within the cluster. In Table 1, we can find that "3d bioprinting (2010)", "additive manufacturing/selective laser (2009)" and "ultrasonic consolidation (2008)", and "technical parameter (2007)" are the research frontiers for 3D printing.

\section{(1) The hottest cluster "additive manufacturing"}

Additive manufacturing is a process of joining materials to make objects from 3D model data, usually layer upon layer (ASTMInternational, 2012). Based on Table 1, the largest cluster, \#0 additive manufacturing, has 68 members, whose average year of publication is 2009 . It is not only the largest cluster but also the second most recent, which indicates that additive manufacturing 
has been a relatively new term, replacing rapid prototyping and other older terms, and drawn more and more people's attention. In addition, a silhouette value of 0.916 shows that cluster $\# 0$ has high quality aggregation. Therefore, the cluster "additive manufacturing" is essential to the literature research.

\section{(2)The emerging research theme " $3 d$ bioprinting"}

The most recently emerging cluster, \#1 $3 d$ bioprinting, contains 63 member references. Its average year of publication is 2010. The printing and patterning in three dimensions of all the components that make up a tissue, or to generate structures analogous to tissues, can be termed 3d bioprinting (Derby, 2012). Nowadays, 3d bioprinting is being applied to regenerative medicine and has made great achievements in the generation and transplantation of several tissues. Multilayered skin, bone, vascular grafts, tracheal splints, heart tissue and cartilaginous structures have already been realized by $3 d$ bioprinting technology (Murphy and Atala, 2014). 
Table 1 Brief summary of top 10 clusters

\begin{tabular}{|c|c|c|c|c|c|c|}
\hline \multirow{2}{*}{$\begin{array}{l}\text { Clus } \\
\text { ter }\end{array}$} & \multirow{2}{*}{$\begin{array}{c}\text { Siz } \\
\text { e }\end{array}$} & \multirow{2}{*}{$\begin{array}{l}\text { Silhou } \\
\text { ette }\end{array}$} & \multicolumn{3}{|c|}{ Label } & \multirow{2}{*}{$\begin{array}{c}\text { Average } \\
\text { year of } \\
\text { publication }\end{array}$} \\
\hline & & & TFIDF & LLR & $\mathrm{MI}$ & \\
\hline & & & & & Additive & \\
\hline 0 & 68 & 0.916 & Selective laser & $\begin{array}{c}\text { Additive } \\
\text { manufacturing }\end{array}$ & $\begin{array}{c}\text { manufacture } \\
\text { d metallic } \\
\text { part }\end{array}$ & 2009 \\
\hline 1 & 63 & 0.899 & Microfluidic & $3 \mathrm{~d}$ bioprinting & $\begin{array}{l}\text { Application } \\
\text { area }\end{array}$ & 2010 \\
\hline 2 & 50 & 0.724 & Natural polymer & $\begin{array}{l}\text { Solvent-free } \\
\text { visible } \\
\text { light-cured } \\
\text { resin }\end{array}$ & $\begin{array}{c}\text { Mechanical } \\
\text { characteristic }\end{array}$ & 2002 \\
\hline 3 & 41 & 0.973 & $\begin{array}{l}\text { Solid free-form } \\
\text { Fabrication }\end{array}$ & $\begin{array}{c}\text { Drug delivery } \\
\text { Device }\end{array}$ & $\begin{array}{c}\text { Slurry } \\
\text { chemistry } \\
\text { Control }\end{array}$ & 1993 \\
\hline 4 & 41 & 0.802 & $\begin{array}{l}\text { Technical } \\
\text { parameter }\end{array}$ & $\begin{array}{l}\text { Technical } \\
\text { parameter }\end{array}$ & Bioactive & 2007 \\
\hline 5 & 35 & 1 & $\begin{array}{c}\text { Rapid } \\
\text { prototyping } \\
\text { technologies }\end{array}$ & $\begin{array}{c}\text { Rapid } \\
\text { prototyping } \\
\text { technologies }\end{array}$ & $\begin{array}{c}\text { Rapid } \\
\text { prototyping } \\
\text { technologies }\end{array}$ & 1995 \\
\hline 6 & 28 & 0.964 & $\begin{array}{c}\text { Local } \\
\text { composition } \\
\text { control }\end{array}$ & $\begin{array}{l}\text { Local } \\
\text { composition } \\
\text { control }\end{array}$ & $\begin{array}{l}\text { Using rp } \\
\text { technology }\end{array}$ & 1997 \\
\hline 7 & 25 & 0.977 & $\begin{array}{c}\text { Ultrasonic } \\
\text { consolidation }\end{array}$ & $\begin{array}{c}\text { Ultrasonic } \\
\text { consolidation }\end{array}$ & Powder bed & 2008 \\
\hline 8 & 21 & 0.947 & $\begin{array}{c}3 d \text { powder } \\
\text { printing }\end{array}$ & $\begin{array}{c}\text { 3d powder } \\
\text { printing }\end{array}$ & Bioactive & 2005 \\
\hline 9 & 18 & 0.98 & Surgery & Surgery & Surgery & 1995 \\
\hline
\end{tabular}

3.2 Landmark references and burst references as indicators of hotspots and trends

Figure 5 shows the landmark references and burst references bibliographic landscape of the 
co-cited references network for 3D printing generated by CiteSpacelll. The different size of "tree rings" node depends on the number of times per year it has been cited. The different colors of "tree rings" are used to match the year shown in the spectrum above the main image. Lines that connect nodes are co-cited links and the different colors of these lines are set to show when a connection was made for the first time. A blue color represents ab earlier connection, and an orange color indicates a recent connection. The burst references are marked as red circles and the size of each circle represents the burst strength. In addition, the authors and publication years of burst references are also labeled in black to make them easier to see.

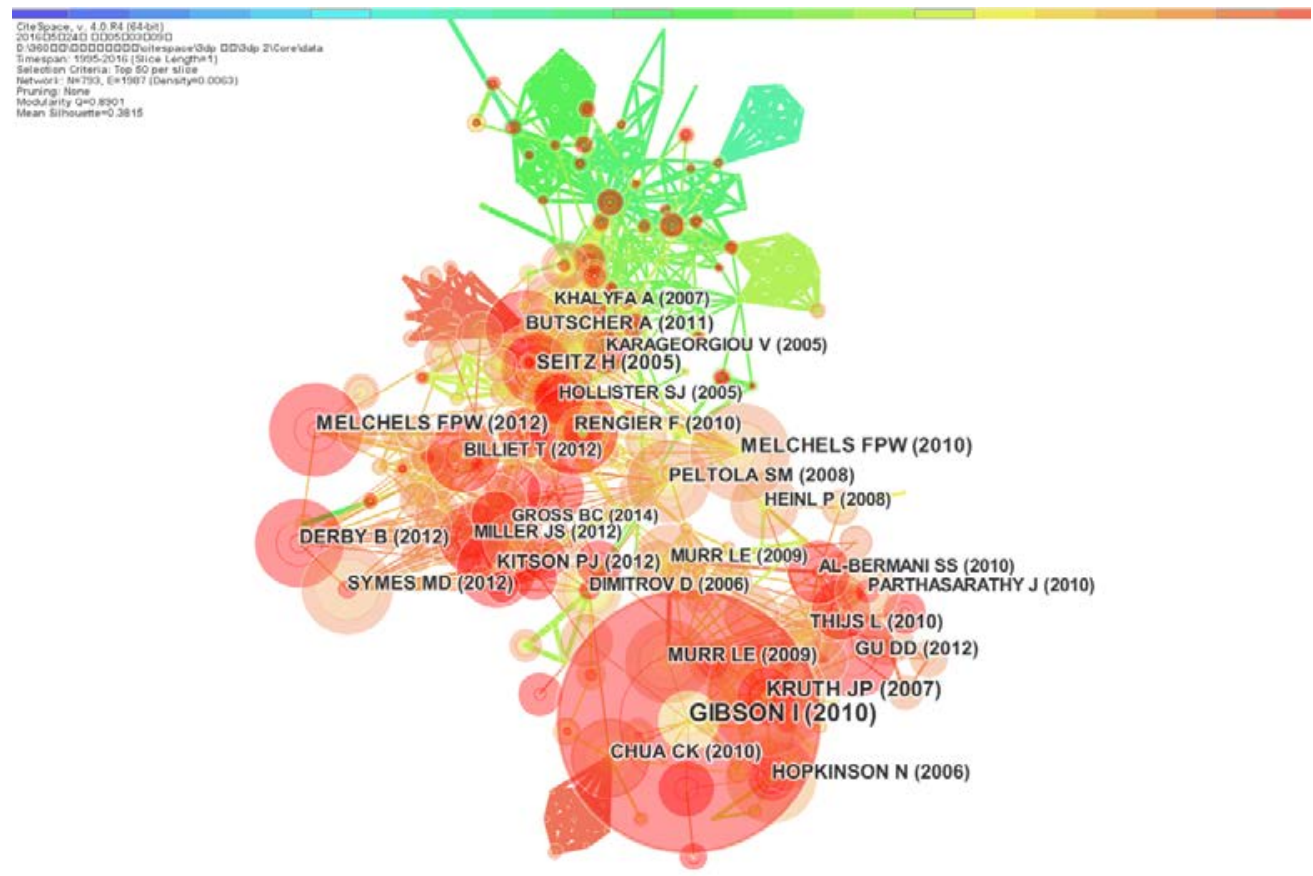

Figure 5 landmark references and burst references bibliographic landscape

\subsubsection{Analysis based on landmark references}

Table 2 lists the top 10 cited references ranked by citation counts from 1995 to 2016 . From the point of view of influence, it is obvious that Gibson et al. (2010), Kruth et al. (2007) and Melchels et al. (2010) are the most important landmark references. In terms of the date aspect of the study, articles 2, 4 and 6 were published from 2005 to 2007, which corresponds to the earlier research hotspots about 3D printing. Articles 1, 3 and 9 were published in 2010, which reflects the hotspots in recent years. Articles 5, 7, 8 and 10 were published in 2012, which indicates the emerging trends. Data analysis shows that $70 \%$ of the top 10 cited references were published since 2010 , and $72.7 \%$ of citation counts in table 2 were also from the articles published since 2010 . It is clear that the hotspots of 3D printing have been constantly changing and have also grown quickly since 
2010.

From the perspective of research content, the following phenomena can be found.

Landmark references 1, 2, 6 and 10 are all from cluster \#0, which reflects the different hotspots coming out of "additive manufacturing". Among of them, the top landmark reference is Gibson et al. (2010), which is a book on "additive manufacturing" published by Springer, with a citation count of 141 . It has the largest number of citation counts even though it was published in 2010, which indicates the importance of the book in this research field. This book provides a basic overview of the additive manufacturing process, describes the different technologies in detail, and introduces how to apply different technologies in different settings. The second landmark reference with great significance is Kruth et al. (2007) with a citation count of 64 . The paper studied which type of "laser-induced consolidation" could be applied to corresponding materials. Landmark reference 6 (Hopkinson et al., 2006), is another book, entitled "rapid manufacturing: an industrial revolution for the digital age". It covers design potential, customer input and customization, emerging processes, material issues, production economics, management and applications of "rapid prototyping". This book is a groundbreaking text that provides excellent coverage of this fast emerging industry, and it is filled with images depicting the vast array of products being commercially manufactured. Landmark reference 10 ( $\mathrm{Gu}$ et al., 2012) studied "laser additive manufacturing" of metallic components, establishing a relationship between material, process, and metallurgical mechanisms for laser based additive manufacturing of metallic components.

Articles 5, 7, 8 and 9 are all from cluster \#1, and are the research hotspots coming out of the "3d bioprinting" field. The fifth landmark reference was published in Progress in Polymer Science by Melchels et al. (2012) as a review paper. It discusses the rationale for engineering "tissues and organs" by combining computer-aided design with additive manufacturing technologies. Article 7 (Symes et al., 2012) put forward an attractive but unexplored application using a 3D printer to initiate "chemical reactions" by printing the reagents directly into a 3D reactionware matrix, thus putting reactionware design, construction and operation under digital control. Article 8 was published in Science by Derby (2012) and is also a review paper like article 5. It reviews the printing and prototyping of "tissues and scaffolds". Article 8 (Rengier et al., 2010) points out that $3 \mathrm{D}$ rapid prototype models could be produced by special printers based on CT or MRI volumetric "medical images".

Articles 3 and 4 are from cluster \#4. They both researched problems on "technical parameters". Article 3 (Melchels et al., 2010) discussed the characteristic features of the "stereolithography" technique and compared it with other SFF techniques. Article 4 (Seitz et al., 2005), entitled 
"three-dimensional printing of porous ceramic scaffolds for bone tissue engineering" was the earliest published of the top 10 references. It proposed a new process chain for custom-made three-dimensional "porous ceramic scaffolds" for bone replacement.

Table 2 Top 10 cited references ranked by citation counts

\begin{tabular}{cccc}
\hline Sequence & References & $\begin{array}{c}\text { Citation } \\
\text { counts }\end{array}$ & Cluster\# \\
\hline & Gibson I, 2010, ADDITIVE MANUFACTURING & & \\
1 & TECHNOLOGIES: RAPID PROTOTYPING TO DIRECT & 141 & 0 \\
& DIGITAL MANUFACTURING, V, P1 & & \\
2 & Kruth JP, 2007, CIRP ANN-MANUF TECHN, V56, P730 & 64 & 0 \\
3 & Melchels FPW, 2010, BIOMATERIALS, V31, P6121 & 54 & 4 \\
4 & Seitz H, 2005, J BIOMED MATER RES B, V74B, P782 & 50 & 4 \\
5 & Melchels FPW, 2012, PROG POLYM SCI, V37, P1079 & 50 & 1 \\
& Hopkinson N, 2006, RAPID MANUFACTURING: AN & & \\
6 & INDUSTRIAL REVOLUTION FOR THE DIGITAL AGE, & 49 & 0 \\
7 & V, P1 & 49 & 1 \\
9 & Rengier F, 2010, INT J COMPUT ASS RAD, V5, P335 & 47 & 1 \\
10 & Gu DD, 2012, INT MATER REV, V57, P133 & 46 & 0 \\
\hline
\end{tabular}

\subsubsection{Analysis based on burst references}

The emerging trends in a research area can be captured by articles receiving a surging frequency of citations (Kim and Chen, 2015). Those articles cited more frequently that others in a relatively short period of time are called burst references. The burst references with the highest strength values, may be seen as the foci of research in a community, since these articles have attracted the attention of peer scholars. For drawing a more representative conclusion, we will only focus on the literature with the strongest burst in a group of articles bursting at the same time. Table 3 shows the top 10 references with the strongest burst values for particular start years during the period 1995-2016, listed chronologically. Table 3 provides an insight into the changing trends of the hotspots in 3D printing research. The dark green line represents the time after an article is published, and the red line represents the burst duration for the article.

From the Table 3, we see that the paper bursting earliest during 1995-2016 was Sachs et al. 
(1992), published in the Journal of Manufacturing Science and Engineering. Its burst started in 1996 and ended in 2000 as the red line shows, reflecting the earliest hotspot for 3D printing research. This article pointed out that "3D printing" is a process for the manufacture of tooling and functional prototype parts directly from computer models, and it may be applied to the production of metal, ceramic, and metal/ceramic composite parts. The paper also discussed how 3D printing works. Table 3 also shows that there was no strong burst literature in the top 10 from 1997 to 1999 , which indicates that research on 3D printing was not widely spread over many topics during that time.

Table 3 Top 10 of references with the strongest burst in the same start year

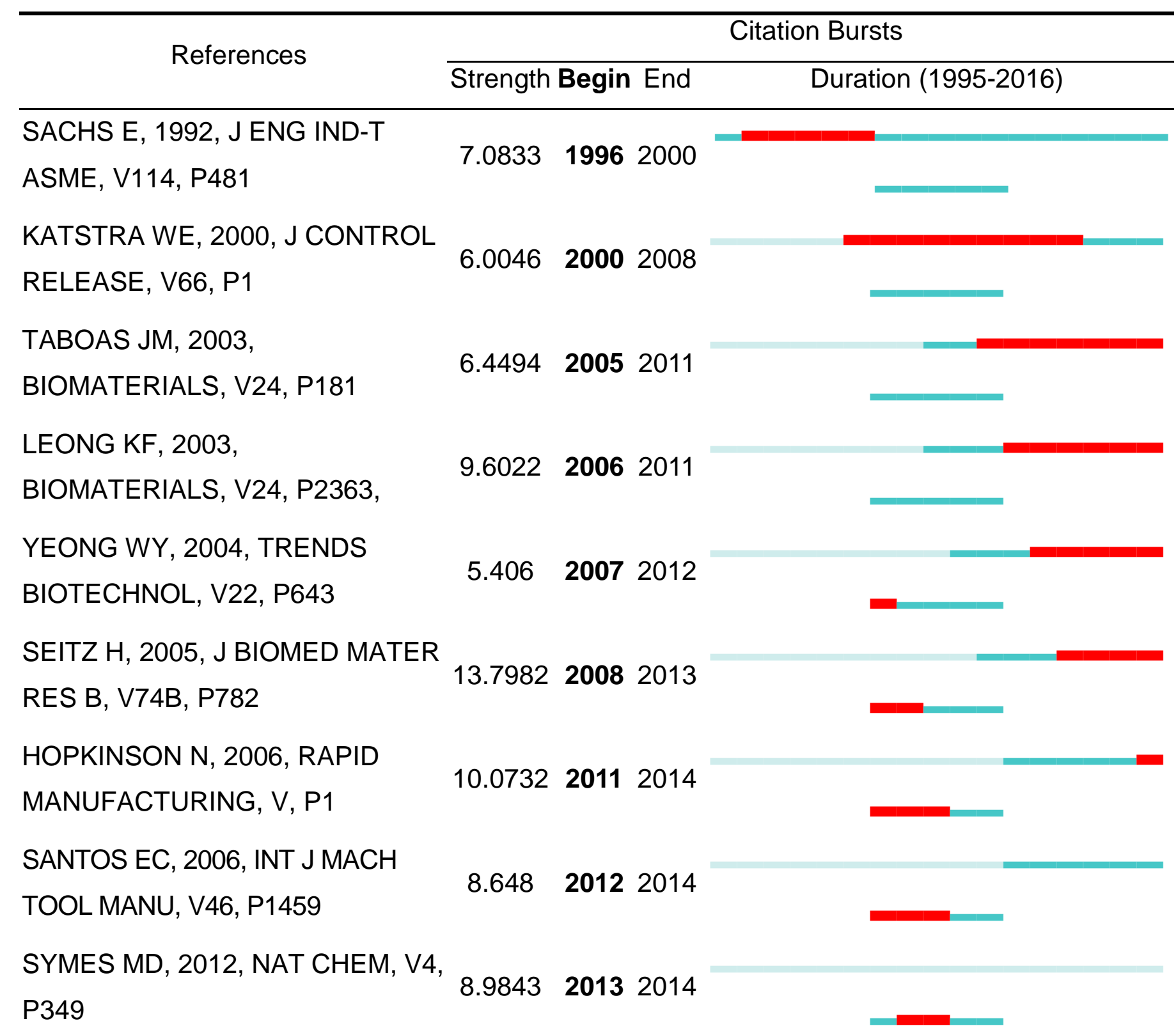


Four years later, Katstra et al. (2000) published a paper entitled "Oral dosage forms fabricated by Three Dimensional Printing ${ }^{\mathrm{TM}}$ ", which burst quickly in the same year and kept going for nine years until 2008 as shown in Figure 6 and was consequently, the most persistent hotspot. In this paper, 3D printing is considered as a novel technique used in the fabrication of "complex oral dosage delivery pharmaceuticals". The authors found 3D printing is capable of accurately constructing dosage forms with active content and samples fabricated with this technique are comparable to other standard pharmaceutical products. Five years after that, an article by Taboas et al. (2003) burst from 2005 until 2011. This paper developed several methods for casting locally and globally porous, biomimetic and composite "3D polymer-ceramic scaffolds". These could provide precise control over scaffold shape, material, porosity and internal pore architecture. The above two papers reflect the following phenomena: first, the medical field began to be a research hotspot for 3D printing in 2000-2011; second, during the period from 2001 to 2004, there was still no strong burst literature in the top 10 strongest burst references, which suggests that 3D printing research had not yet appeared as a comprehensive outbreak at that time.

Since 2005, burst literature has emerged every year in the top 10 strongest burst references except in 2009-2010. The research hotspots for 3D printing continue to increase corresponding to research entering the stage of a comprehensive outbreak. Leong et al. (2003) reviewed the application/potential application of advanced solid freeform fabrication (SFF) techniques in creating "tissue engineering (TE) scaffolds". The citation burst of this paper lasted for 5 years from 2006 to 2011. Seitz et al. (2005) already appearing in Table 3 as "porous ceramic scaffolds" burst here in 2008, lasting for 5 years as shown in Figure 7 with a high burst strength of 13.7982. Its burst strength is the second strongest, which shows that a large number of scholars were interested in this article. These two articles show that the related research on "scaffolds" has become a hotspot in the field of 3D printing continuously in recent years. Yeong et al. (2004) bursting in 2007 and Hopkinson et al. (2006) bursting in 2011 together make "rapid prototyping" a research hotspot. In 2012, with the emergence of a paper entitled "Rapid manufacturing of metal components by laser forming" by Santos et al. (2006), "laser-forming techniques" that include selective laser sintering, selective laser melting and 3-D laser cladding became the newest hotspot. After that, The article with the strongest citation burst in 2013 was written by Symes et al. 
(2012) on "chemical reactions". It burst late in 2013 and lasted for only 2 years. It is also one of the top 10 cited references. This fully reflects the importance of this article in the research field of 3D printing. The newest burst reference (Gibson et al., 2010) on "additive manufacturing" needs to be emphasized again as the most important landmark reference in the above, for it has the highest burst strength of 13.9937 even though it was the most recent burst, beginning in 2014. It shows that the research contents of this literature has been highly recognized and valued by academic circles.

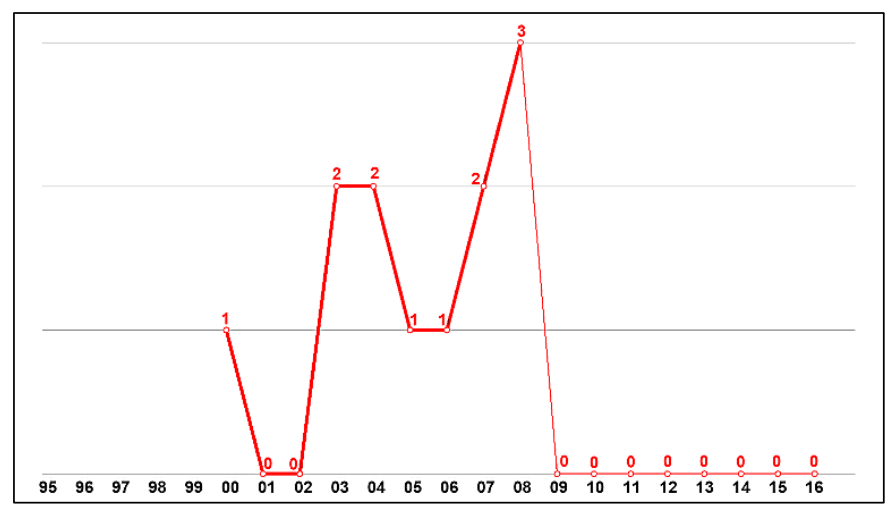

Figure 6 Citation history of Katstra et al. (2000)

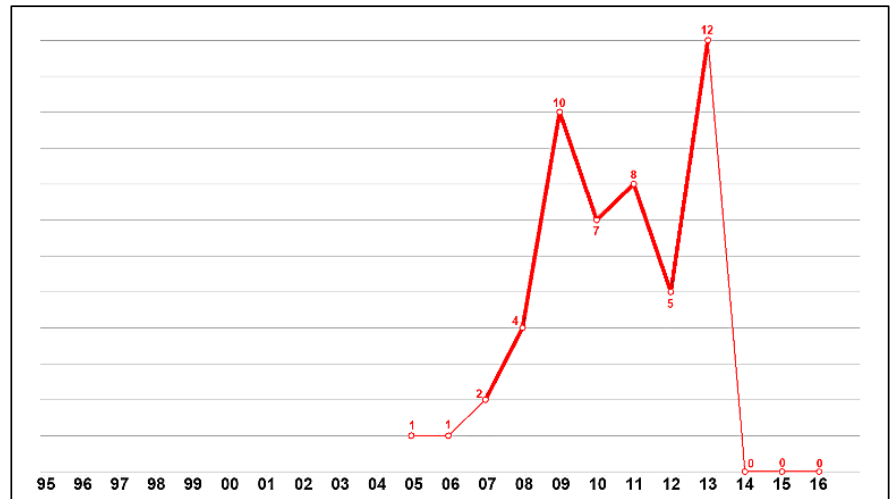

Figure 7 Citation history of Seitz et al. (2005)

\subsection{Keywords as indicators of hotspots and trends}

Figure 8 shows the knowledge landscape of co-occurring keywords network for 3D printing. The network generated for literature published from 1995 to 2016 contains a total of 537 keywords and 1736 links. The nodes are keywords and the different colors of these "tree rings" are used to match the year shown in the spectrum above the main image. The thickness of "tree rings" represents the number of uses of a co-occurring keyword in a particular year. Lines that connect nodes are called co-occurring links and the different colors of these lines are set to show when a connection was made for the first time. A blue color represents an earlier connection, and an 
orange color indicates a later connection. Also, nodes with an emergent property are visualized in red. From Figure 8, we can tell the research on 3D printing have spread across many fields, and main hot fields include "additive manufacturing", "3d printing", "fabrication", "mechanical property", "scaffold", "microstructure", "rapid prototyping" and so on.

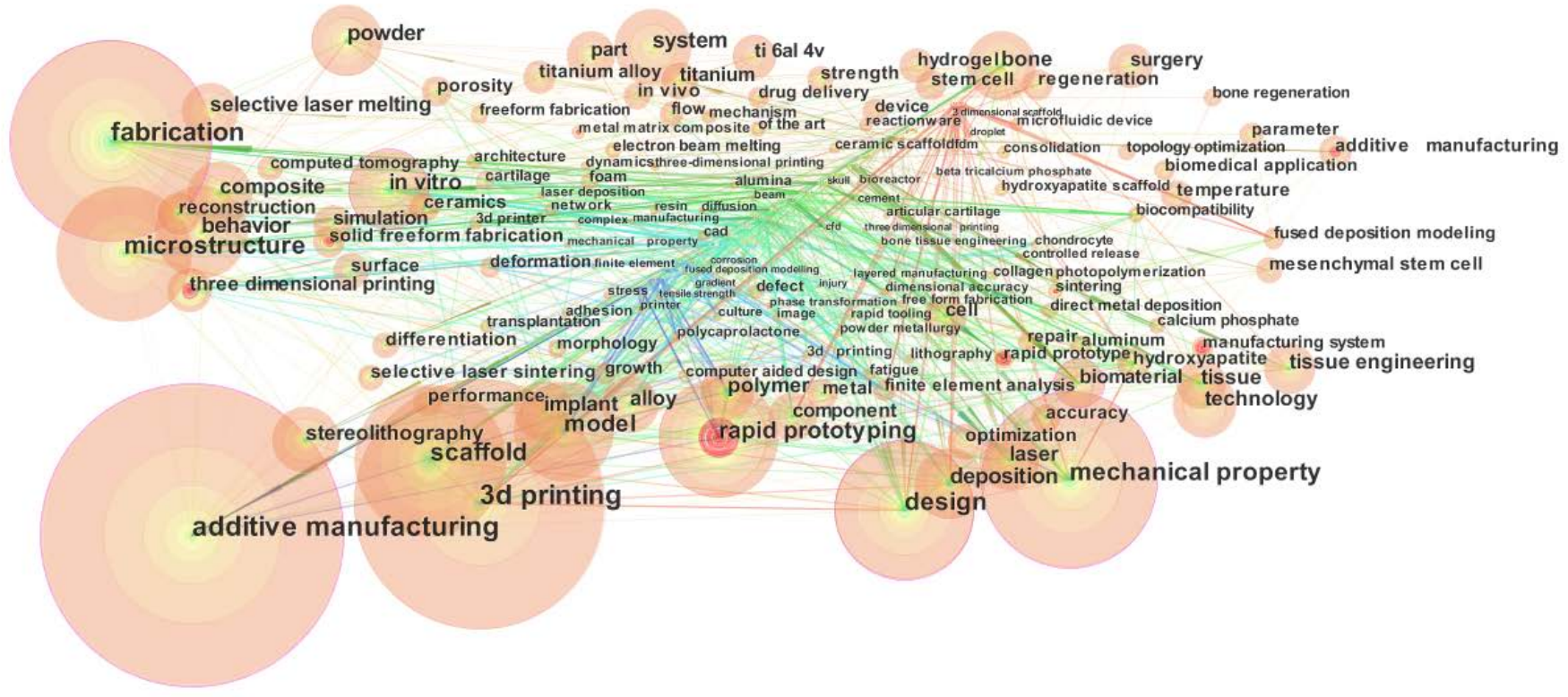

Figure 8 The co-occurring keywords visualization for 3D printing

In order to explain the research hotspots and emerging trends of 3D printing more precisely based on the above research, burst keywords function (Chen, 2006) is used as indicators to analyze the issue. After excluding conceptual keywords mentioned above such as rapid prototyping, 3D printing, additive manufacturing, etc., the top 10 keywords with strong bursts between 1995 and 2016 in 3D printing research are listed in Table 4. In the table, the blue line represents the total time span and the red line indicates the burst duration. Referring to the table, we can identify the important themes of 3D printing research across two decades. First of all, we can see that these burst keywords mainly appeared after 2000, which shows the related research on 3D printing has achieved a concentrated development in twenty-first Century. Besides, these 10 keywords can classified into 3 categories, namely technology, material, and medicine. "Solid freeform fabrication", "electron beam melting", "selective laser sintering" and "surface roughness" can be classified as technical category, which indicates that technological progress is the important 
area of 3D printing research. "Aluminum" and "titanium" can be classified as material category, which shows that the material issues are still an important issue in the industrialization of 3D printing. "Hydroxyapatite scaffold", "biomedical application" and "stem cell" belongs to medicine category, which proofs that the medical industry is the most representative in the application research. Based on the burst duration and burst strength of these keywords, "Solid freeform fabrication" burst earliest in 2003, lasts the longest from 2003 to 2012 and owns the biggest burst value, which illustrates "solid freeform fabrication" technology is an important 3D printing technology, receiving extensive attention. What's more, "stem cell" burst latest in 2014 and continues so far, which means "stem cell" is a hotspot and emerging trend of 3D printing research.

Table 4 Top 10 keywords with strong bursts in 3D printing research

\begin{tabular}{|c|c|c|c|c|}
\hline Keywords & $\begin{array}{l}\text { Streng } \\
\text { th }\end{array}$ & $\begin{array}{c}\text { Begi } \\
n\end{array}$ & End & $1995-2016$ \\
\hline $\begin{array}{c}\text { solid freeform } \\
\text { fabrication }\end{array}$ & 6.658 & 2003 & $\begin{array}{c}201 \\
2\end{array}$ & \\
\hline aluminum & 5.5632 & 2006 & $\begin{array}{c}201 \\
1\end{array}$ & \\
\hline $\begin{array}{c}\text { hydroxyapatite } \\
\text { scaffold }\end{array}$ & 4.0947 & 2010 & $\begin{array}{c}201 \\
1\end{array}$ & \\
\hline titanium & 3.5642 & 2010 & $\begin{array}{c}201 \\
1\end{array}$ & - \\
\hline $\begin{array}{c}\text { electron beam } \\
\text { melting }\end{array}$ & 4.1248 & 2010 & $\begin{array}{c}201 \\
2\end{array}$ & \\
\hline $\begin{array}{l}\text { selective laser } \\
\text { sintering }\end{array}$ & 4.5711 & 2011 & $\begin{array}{c}201 \\
2\end{array}$ & - \\
\hline surface roughness & 4.4231 & 2011 & $\begin{array}{c}201 \\
3\end{array}$ & E \\
\hline $\begin{array}{l}\text { biomedical } \\
\text { application }\end{array}$ & 3.7508 & 2011 & $\begin{array}{c}201 \\
4\end{array}$ & - \\
\hline $\begin{array}{l}\text { computer aided } \\
\text { design }\end{array}$ & 4.3512 & 2011 & $\begin{array}{c}201 \\
3\end{array}$ & 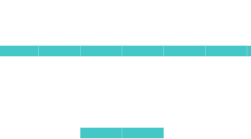 \\
\hline
\end{tabular}




\section{Conclusion and discussion}

\subsection{Conclusion and Findings}

Hotspots and trends of 3D printing have been identified based on structural and temporal properties derived from the relevant publications from 1995 to 2016 using CiteSpacelll. In order to summarize clearly the findings of the different indicators from the clusters, burst references, keywords, and landmark references, and to aid analysis, we have drawn a comprehensive map visualizing hotspots and trends of 3D printing as shown in Figure 9.

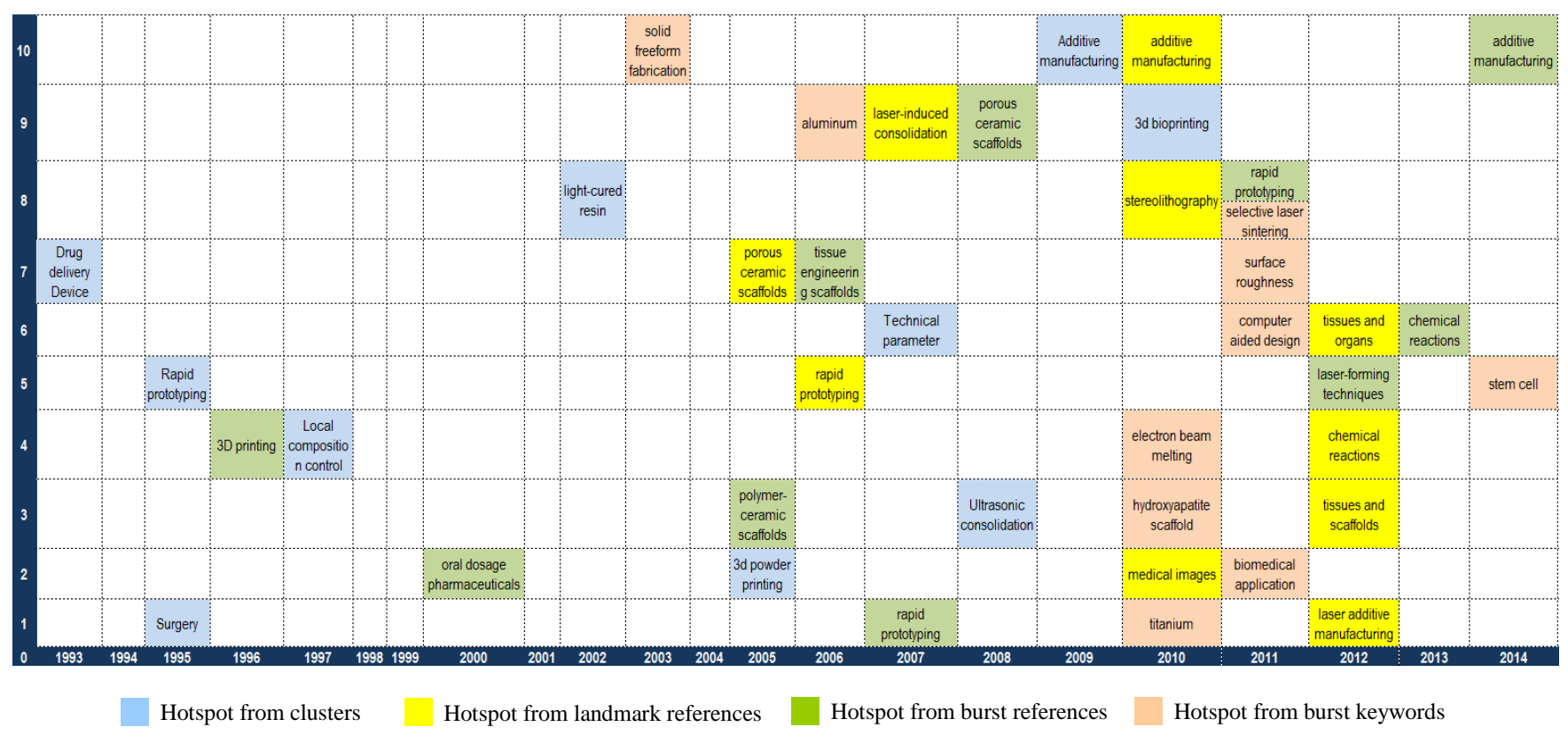

Figure 9 Overall perspective of hotspots and trends of 3D printing

Figure 9 is a summary of the results from clusters, landmark references, burst references and burst keywords. The $x$-axis represents time (year) and the $y$-axis represents the relative importance of hotspots, divided into 10 levels. For cluster analysis, hotness level is judged according to the size of clustering; for landmark references, it is judged by citation counts; for burst references and burst keywords, it is decided according to their burst strength. Based on the above, we can draw the following comprehensive conclusions. (1) hotspots appeared first in 1993, and grew rapidly from 2005, and peaked in 2013; (2) without considering those conceptual terminology such as rapid prototyping, 3D printing, additive manufacturing, etc., hotspots are mainly concentrated in the medical field (appearing 11 times including "surgery", "scaffold", "drug", 
"stem cell" and so on), the material field (appearing 3 times including "light-cured resin", "aluminum", "titanium"), and the technology field (appearing 13 times including "ultrasonic consolidation", "laser-induced consolidation", "stereolithography", "selective laser sintering", "electron beam melting" and so on ); (3) the hotspots in "medical field" appear earliest, and remain extremely active; (4) "3D bioprinting", "titanium", "stem cell", "chemical reaction" and so on are the emerging hotspots in recent years. Especially, "stem cell" and "chemical reaction" burst very recently (from 2012), which shows that the chemistry field is becoming the research frontier of 3D printing, and the medical field is still the research forefront of 3D printing.

\subsection{Limitations and future outlook}

Although the Web of Science Core Collection was chosen as the data source, the authors admit the possibility of missing some important research publications on 3D printing. In addition, we are also aware that relevant records could be missing if the query phrases used for topic searches did not match some records. Also, in order to improve the quality of data, this study selected only articles and books as the research objects, which may also omit some important research results (e.g. PhD theses). Furthermore, "Top 50 per slice" was set as the standard of data extraction in CiteSpacelll in our research, which will also have had some effect on the analyses. Therefore, the results of the study may not be completely consistent with the actual situation. In a follow-up study, the authors will optimize the related parameters so as to improve the quality of the searches.

The development of 3D printing has shown some new trends in recent years. For example, the cost of 3D printing is rapidly declining, product quality and speed of 3D printing has been able to meet the requirements of more and more customers. Obviously, these new trends are accelerating the industrialization aspect of 3D printing technology. However, the commercial operation of a new technology is often accompanied by complex challenges. As a result, we predict some business operation issues about 3D printing technology, such as business model innovation, brand building, channel management, will be the emerging hotspots in the near future. Also, the development of 3D printing may be also affected by emerging technologies like big data, cloud computing, Internet of Things, artificial intelligence, robotics, virtual reality and so on. Therefore, we believe the fusion of 3D printing and these emerging fields is likely to lead to the birth of new research hotspots.

Acknowledgments This work is supported by China's National Natural Science Foundation under Grant No. 71572031, the economic and social development project from Liaoning Provincial Federation of Social Science Circles under Grant NO. 2016lslktjjx-13, the humanities and social sciences research project from Education Department of Liaoning Province Project 
under Grant No.W2014051, Liaoning Planning Fund of Philosophy and Social Science Project under Grant NO.L12CJY039, and 2014 Anshan Science and Technology Planning Projects.

\section{References}

Andersson, S.-I., Kjellander, N. and Rodesjö, B. (1985), "Design and field tests of a new membrane distillation desalination process", Desalination, Vol. 56, pp. 345-354.

ASTMInternational. (2012), "Standard terminology for additive manufacturing technologies (ASTM F2792-12a)", in. ASTM International, West Conshohocken, PA.

Bara, J. E., Hawkins, C. I., Neuberger, D. T. and Poppell, S. W. (2013), "3D printing for CO 2 capture and chemical engineering design", Nanomaterials and Energy, Vol. 2 No. 5, pp. 235-243.

Bassoli, E., Gatto, A., Iuliano, L. and Violante, M. G. (2007), "3D printing technique applied to rapid casting", Rapid Prototyping Journal, Vol. 13 No. 3, pp. 148-155.

Bhasin, V. and Bodla, M. R. (2014), "Impact of 3D printing on global supply chains by 2020", Massachusetts Institute of Technology.

Bhudolia, S., Fischer, S., He, P., Yue, C. Y., Joshi, S. C. and Yang, J. (2015), "Design, Manufacturing and Testing of Filament Wound Composite Risers for Marine and Offshore Applications", in Materials Science Forum. Trans Tech Publ, pp. 337-343.

Campbell, R. I., Bourell, D. and Gibson, I. (2012), "Additive manufacturing: rapid prototyping comes of age", Rapid Prototyping Journal, Vol. 18 No. 4, pp. 255-258.

Campbell, T., Williams, C., Ivanova, O. and Garrett, B. (2011), "Could 3D printing change the world", Technologies, Potential, and Implications of Additive Manufacturing, Atlantic Council, Washington, $D C$.

Chen, C. (2004), "Searching for intellectual turning points: Progressive knowledge domain visualization", Proceedings of the National Academy of Sciences, Vol. 101 No. suppl 1, pp. 5303-5310.

Chen, C. (2006), "CiteSpace II: Detecting and visualizing emerging trends and transient patterns in scientific literature", Journal of the American Society for information Science and Technology, Vol. 57 No. 3, pp. 359-377.

Chen, C. (2014), "The CiteSpace manual", available at: http://cluster.ischool.drexel.edu/ cchen/citespace/CiteSpaceManual.pdf $\quad$ (accessed 2014-12-13).

Chen, C., Dubin, R. and Kim, M. C. (2014a), "Emerging trends and new developments in regenerative medicine: a scientometric update (2000 - 2014)", Expert Opinion on Biological Therapy, Vol. 14 No. 9, pp. 1295-1317.

Chen, C., Dubin, R. and Kim, M. C. (2014b), "Emerging trends and new developments in regenerative medicine: a scientometric update (2000 - 2014)", Expert Opinion on Biological Therapy, Vol. 14 No. 9, pp. 1295-1317.

Chen, C., Dubin, R. and Kim, M. C. (2014c), "Orphan drugs and rare diseases: a scientometric review (2000-2014)", Expert Opinion on Orphan Drugs, Vol. 2 No. 7, pp. 709-724.

Chen, C., Dubin, R. and Schultz, T. (2014), "Science Mapping", in Khosrow-Pour, M. (Ed.), Encyclopedia of Information Science and Technology. IGI Global, New York, pp. 271-284. 
Chen, C., Ibekwe-SanJuan, F., SanJuan, E. and Weaver, C. (2006), Visual analysis of conflicting opinions, leee, New York.

Chen, C., Ibekwe-SanJuan, F. and Hou, J. (2010), "The structure and dynamics of cocitation clusters: A multiple-perspective cocitation analysis", Journal of the American Society for Information Science and Technology, Vol. 61 No. 7, pp. 1386-1409.

Cho, H., Choi, Y.-J., Lee, S., Koo, J. and Huang, T. (2015), "Comparison of hollow fiber membranes in direct contact and air gap membrane distillation (MD)", Desalination and Water Treatment No. ahead-of-print, pp. 1-8.

Christensen, C. (2013), The innovator's dilemma: when new technologies cause great firms to fail, Harvard Business Review Press, Boston.

Chu, C., Graf, G. and Rosen, D. W. (2008), "Design for additive manufacturing of cellular structures", Computer-Aided Design and Applications, Vol. 5 No. 5, pp. 686-696.

Chua, C. K. and Leong, K. F. (2004), 3D printing and additive manufacturing: principles and applications, World Scientific Publishing Co Pte Ltd, Engelska.

Chua, C. K., Matham, M. V., Kim, Y.-J. and Yeong, W. Y. (2016), Lasers in 3d Printing and Manufacturing, World Scientific.

Cobo, M. J., López-Herrera, A. G., Herrera-Viedma, E. and Herrera, F. (2011), "Science mapping software tools: Review, analysis, and cooperative study among tools", Journal of the American Society for Information Science \& Technology, Vol. 62 No. 7, pp. 1382-1402.

Derby, B. (2012), "Printing and prototyping of tissues and scaffolds", Science, Vol. 338 No. 6109, pp. 921-926.

Economist. (2012), "The third industrial revolution", The Economist, Vol. 403 No. 8781, pp. 15.

Gebhardt, A., Schmidt, F.-M., Hötter, J.-S., Sokalla, W. and Sokalla, P. (2010), "Additive manufacturing by selective laser melting the realizer desktop machine and its application for the dental industry", Physics Procedia, Vol. 5, pp. 543-549.

Gibson, I., Rosen, D. W. and Stucker, B. (2010), Additive manufacturing technologies, Springer.

Gu, D., Meiners, W., Wissenbach, K. and Poprawe, R. (2012), "Laser additive manufacturing of metallic components: materials, processes and mechanisms", International materials reviews, Vol. 57 No. 3, pp. 133-164.

Guo, N. and Leu, M. C. (2013), "Additive manufacturing: technology, applications and research needs", Frontiers of Mechanical Engineering, Vol. 8 No. 3, pp. 215-243.

Hopkinson, N., Hague, R. and Dickens, P. (2006), Rapid manufacturing: an industrial revolution for the digital age, John Wiley \& Sons, New York.

Hutmacher, D. W. (2015), "Bioprinting, biofabrication, biomanufacturing? The need for definitions and norms in additive manufacturing in the biomedical sciences", in. CAMBRIDGE UNIV PRESS 32 AVENUE OF THE AMERICAS, NEW YORK, NY 10013-2473 USA.

Jin, Y. and Ji, S. (2013), "Partner choice of supply chain based on 3d printing and big data", Information Technology Journal, Vol. 12 No. 22, pp. 6822-6826.

Johnson, B. H., Kim, K. W., Heath, R. E., Hsieh, B. B. and Butler, H. L. (1993), "Validation of three-dimensional hydrodynamic model of Chesapeake Bay", Journal of Hydraulic Engineering, Vol. 119 No. 1, pp. 2-20.

Karjalainen, I., Domingo, R., Alvarez, R., Melodía Peña, M. and Calvo, R. (2007), "Materials flow improvement in a lean assembly line: a case study", Assembly Automation, Vol. 27 No. 2 , pp. 141-147. 
Katstra, W., Palazzolo, R., Rowe, C., Giritlioglu, B., Teung, P. and Cima, M. (2000), "Oral dosage

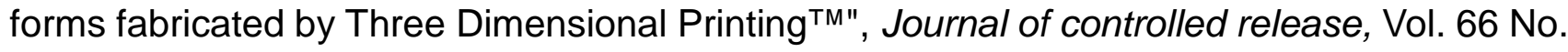
1, pp. 1-9.

Kim, M. C. and Chen, C. (2015), "A scientometric review of emerging trends and new developments in recommendation systems", Scientometrics, Vol. 104 No. 1, pp. 239-263.

Klein, G. T., Lu, Y. and Wang, M. Y. (2013), "3D Printing and Neurosurgery-Ready for Prime Time?", World neurosurgery, Vol. 80 No. 3, pp. 233-235.

Kneissl, D. W. (2013), "3D Printing Materials 2014-2025: Status, Opportunities, Market Forecasts", in. IDTechEx.

Kruth, J.-P., Levy, G., Klocke, F. and Childs, T. (2007), "Consolidation phenomena in laser and powder-bed based layered manufacturing", CIRP Annals-Manufacturing Technology, Vol. 56 No. 2, pp. 730-759.

Lee, J.-Y., Tan, W. S., An, J., Chua, C. K., Tang, C. Y., Fane, A. G. and Chong, T. H. (2016), "The potential to enhance membrane module design with 3D printing technology", Journal of Membrane Science, Vol. 499, pp. 480-490.

Leong, K., Cheah, C. and Chua, C. (2003), "Solid freeform fabrication of three-dimensional scaffolds for engineering replacement tissues and organs", Biomaterials, Vol. 24 No. 13, pp. 2363-2378.

Lipson, H. and Kurman, M. (2013), Fabricated: The New World of 3D Printing, John Wiley \& Sons, New York, United States.

Lipton, J. I., Cutler, M., Nigl, F., Cohen, D. and Lipson, H. (2015), "Additive manufacturing for the food industry", Trends in Food Science \& Technology, Vol. 43 No. 1, pp. 114-123.

Marga, F., Jakab, K., Khatiwala, C., Shepherd, B., Dorfman, S., Hubbard, B., Colbert, S. and Forgacs, G. (2012), "Toward engineering functional organ modules by additive manufacturing", Biofabrication, Vol. 4 No. 2, pp. 022001.

Mathai, J. (2015), "Electrospinning Pvdf Nanoporous Membranes For Use In Air Gap Membrane Distillation To Desalinate Dirty Water".

Melchels, F. P., Domingos, M. A., Klein, T. J., Malda, J., Bartolo, P. J. and Hutmacher, D. W. (2012), "Additive manufacturing of tissues and organs", Progress in Polymer Science, Vol. 37 No. 8 , pp. 1079-1104.

Melchels, F. P., Feijen, J. and Grijpma, D. W. (2010), "A review on stereolithography and its applications in biomedical engineering", Biomaterials, Vol. 31 No. 24, pp. 6121-6130.

Murphy, S. V. and Atala, A. (2014), "3D bioprinting of tissues and organs", Nature biotechnology, Vol. 32 No. 8, pp. 773-785.

Perkins, I. and Skitmore, M. (2015), "Three-dimensional printing in the construction industry: A review", International Journal of Construction Management, Vol. 15 No. 1, pp. 1-9.

Rahim, S. L. and Maidin, S. (2014), "Feasibility Study of Additive Manufacturing Technology Implementation in Malaysian Automotive Industry Using Analytic Hierarchy Process", in Applied Mechanics and Materials. Trans Tech Publ, pp. 715-719.

Ratto, M. and Ree, R. (2012), "Materializing information: 3D printing and social change", First Monday, Vol. 17 No. 7.

Rengier, F., Mehndiratta, A., Tengg-Kobligk, H. V., Zechmann, C. M., Unterhinninghofen, R., Kauczor, H. U. and Giesel, F. L. (2010), "3D printing based on imaging data: review of medical applications", International Journal of Computer Assisted Radiology \& Surgery, Vol. 
5 No. 4 , pp. 335-341.

Sachs, E., Cima, M., Williams, P., Brancazio, D. and Cornie, J. (1992), "Three dimensional printing: rapid tooling and prototypes directly from a CAD model", Journal of Manufacturing Science and Engineering, Vol. 114 No. 4, pp. 481-488.

Santos, E. C., Shiomi, M., Osakada, K. and Laoui, T. (2006), "Rapid manufacturing of metal components by laser forming", International Journal of Machine Tools and Manufacture, Vol. 46 No. 12, pp. 1459-1468.

Seitz, H., Rieder, W., Irsen, S., Leukers, B. and Tille, C. (2005), "Three-dimensional printing of porous ceramic scaffolds for bone tissue engineering", Journal of Biomedical Materials Research Part B: Applied Biomaterials, Vol. 74 No. 2, pp. 782-788.

Serenko, A., Bontis, N., Booker, L., Sadeddin, K. and Hardie, T. (2010), "A scientometric analysis of knowledge management and intellectual capital academic literature (1994-2008)", Journal of Knowledge Management, Vol. 14 No. 1, pp. 3-23.

Song, J. and Hu, X. (2015), "Research on the Review of 3D Printing Technology in Construction", Huazhong Architecture, Vol. 33 No. 2, pp. 7-10.

Sun, J., Peng, Z., Yan, L., Fuh, J. Y. H. and Hong, G. S. (2015), "3D food printing-an innovative way of mass customization in food fabrication", International Journal of Bioprinting, Vol. 1.

Sun, J., Zhou, W., Huang, D., Fuh, J. Y. and Hong, G. S. (2015), "An Overview of 3D Printing Technologies for Food Fabrication", Food and Bioprocess Technology, pp. 1-11.

Symes, M. D., Kitson, P. J., Yan, J., Richmond, C. J., Cooper, G. J., Bowman, R. W., Vilbrandt, T. and Cronin, L. (2012), "Integrated 3D-printed reactionware for chemical synthesis and analysis", Nature Chemistry, Vol. 4 No. 5, pp. 349-354.

Taboas, J., Maddox, R., Krebsbach, P. and Hollister, S. (2003), "Indirect solid free form fabrication of local and global porous, biomimetic and composite 3D polymer-ceramic scaffolds", Biomaterials, Vol. 24 No. 1, pp. 181-194.

Tham, K.-M., Laurello, V. P., Lee, C.-P., Azad, G. S., Martin, N. F., Sansom, D. G. and Hitchman, N. (2015), "Turbine abradable layer with progressive wear zone multi level ridge arrays", in. Google Patents.

Valkenaers, H., Jansen, D., Voet, A., Van Gysel, A. and Ferraris, E. (2014), "Additive manufacturing for concrete: a 3D printing principle", in Proceedings of the 14th euspen International Conference, pp. 139-142.

Wang, C. and Su, Q. (2015), "Evolution and Development Trends of 3D Printing Technology Basedon the Analysis of Literature", Journal of Intelligence, Vol. 34 No. 9, pp. 72-77.

Yeong, W.-Y., Chua, C.-K., Leong, K.-F. and Chandrasekaran, M. (2004), "Rapid prototyping in tissue engineering: challenges and potential", TRENDS in Biotechnology, Vol. 22 No. 12, pp. 643-652. 